\title{
A CONSTRUÇÃO DA PERSONA NA SÁTIRA 6 DE JUVENAL
}

\author{
Leni Ribeiro Leite* \\ Iana Lima Cordeiro** \\ Recebido em: 01/06/2018 \\ Aprovado em: 19/09/2018
}

RESUMO: Analisamos a construção da persona satírica dos primeiros duzentos e oitenta e cinco versos da Sátira 6 do poeta romano Juvenal. Nossa análise utiliza o conceito de persona satírica proposto por William Anderson, em que há a distinção entre a voz do poema e o autor empírico, de forma que não se deve supor que em um poema estejam representadas as opiniões de quem o escreveu, mas que o enunciador daquele texto é uma persona conscientemente construída pelo poeta com vistas a atingir determinados objetivos poéticos. Além disso, utilizamos também o conceito de ethos proposto por Dominique Maingueneau, que afirma que ler um texto é necessariamente construir a imagem de quem o tenha escrito. Em nosso caso, analisamos a imagem construída pela persona de Juvenal na sátira em questão, e chegamos à conclusão de que o ethos construído é de alguém conservador, extremamente avesso a mulheres e ao casamento com elas e um saudosista utópico, que evoca um passado ideal inexistente para justificar as próprias queixas - o que, a nosso ver, só comprova a gratuidade delas.

PALAVRAS-CHAVE: Juvenal; sátira romana; persona satírica; ethos.

\section{THE CONSTRUCTION OF THE SATIRICAL PERSONA IN JUVENAL'S SIXTH SATIRE}

*Professora

Associada, Departamento de Línguas e Letras, Letras Clássicas, Universidade Federal do Espírito Santo. leni.ribeiro@gmail.com

** Mestranda do Programa de PósGraduação em Letras, Universidade Federal do Espírito Santo. iana-cordeiro@hotmail. com

\footnotetext{
ABSTRACT: We study the construction of the satirical persona in the first two hundred and eighty five verses of Juvenal's Satire 6 or Book II. Our analysis is based on William Anderson's concept of satirical persona, which establishes a distinction between the voice of the poem and its empirical author, so that one shouldn't assume that the opinions expressed in the text actually belong to the person who wrote it, but that there is a persona consciously created with the goal of achieving specific poetical purposes. We also make use of Dominique Maingueneau's concept of discursive ethos: according to Maingueneau, reading a text implies creating a mental
} 
image of who may have written it. In our present case, we analyzed the satirical persona's image and the conclusion to our study is that the ethos presented here is of someone who is conservative, extremely averse to women and to marrying them, and who evokes a long-lost, ideal and nonexistent past to justify his own complaints - which only attest to how groundless they are.

KEYWORDS: Juvenal; Roman satire; satirical persona; ethos.

\section{INTRODUÇÃO}

J

uvenal, satirista romano que se estima ter vivido durante o século II d.C., sofre da mesma escassez de informações biográficas que acomete tantos outros autores da Antiguidade. Virtualmente, nada se sabe ao certo sobre a vida e as circunstâncias do satirista: não temos certeza nem da veracidade de seu nome, Décimo Júnio Juvenal. O que temos de mais concreto é que Juvenal aparece como destinatário de três epigramas de Marcial (7.24, 7.91, 12.18), escritos em 92 d.C. e 101-2 d.C., que falam das habilidades retóricas do poeta e o descrevem como uma pessoa de vida agitada em Roma. Braund (2004, p. 19) afirma que o dito por Marcial, no que se refere ao conhecimento de retórica de Juvenal, é confirmado pela obra: as Sátiras refletem um treinamento de retórica recebido por membros da elite romana. Logo, é possível supor que o poeta pertencesse à elite como antes dele os satiristas Lucílio e Pérsio -, tendo em vista a ausência de dedicatória de seus poemas a um patrono.

A obra de Juvenal é composta exclusivamente por sátiras. De acordo com a síntese de Susanna Braund (2004, p. 3), a sátira romana era escrita em hexâmetro datílico, com uma linguagem que variava de rebuscada a baixa, e suas composições podiam ser de curta a média extensão, entre 50 e 250 versos. Frequentemente havia a presença de monólogo autobiográfico e era possível que ocorressem diálogos, narrativas ou epístolas. O conteúdo temático das sátiras também permitia variação, podendo abordar moralidade, literatura e educação. Por essa ampla flexibilidade de linguagem, tema e extensão, a sátira é tida como um gênero de difícil definição. Charles Knight (2004, p. 4) a define como pré-genérica, pois é antes uma exploradora de outros gêneros do que um gênero em si mesma. Similar afirmação faz Daniel Hooley (2007, p. 2), para quem a sátira é uma criança genérica de outros gêneros, uma mistura de linhagens com um problema de identidade que dura toda a sua existência. $\mathrm{O}$ autor pontua que uma evidência dessa incerteza seria uma constante menção, na sátira, ao seu próprio gênero, seus limites, seu lugar - a essa tendência Hooley denomina "autoconsciência patológica".

A obra juvenaliana é composta por cinco livros que contêm, no total, dezesseis sátiras: cinco sátiras formam o primeiro livro; apenas uma, a sexta, é a totalidade do livro dois; o terceiro e o quarto livros contêm três sátiras cada; o quinto fecha a obra com as últimas quatro sátiras. No entanto, se consideramos a totalidade da obra, existe uma clara mudança de tom na voz enunciadora dos poemas, em especial quando se consideram os dois primeiros livros em relação aos seus subsequentes: a extrema agressividade das primeiras seis sátiras - a 
indignatio (indignação), muitas vezes tomada como marca registrada do autor ${ }^{1}$ - não vai adiante, dando lugar a um tom mais contido e mesmo filosófico, em especial nas últimas sátiras de sua obra. Já temos um artigo sobre o primeiro livro, "A construção satírica no Livro I de Juvenal" (2017), e aqui nos propomos a analisar esse momento final em que a indignação se apresenta. Essa observação nos direciona para uma questão essencial dentro da crítica juvenaliana: as formas de interpretação dessa mudança de tom dependem da aceitação (ou não) e das nuances de um conceito específico, o de persona satírica, que nos interessará neste artigo, em que buscaremos analisar a construção da persona satírica juvenaliana justamente no poema que marca a transição de tom: a sexta sátira, que ocupa a totalidade do segundo livro.

\section{Persona e ethos}

A aplicação do conceito de persona na interpretação e análise de sátiras romanas foi pioneiramente apresentada por William Anderson (1964), ${ }^{2}$ e se propõe como uma resposta à até então amplamente realizada leitura biografista dos poemas, sobre a qual convém discorrer brevemente. A prática da análise biografista, entendida aqui como aquela que busca no texto informações biográficas sobre seu autor, remonta à Antiguidade - Susanna Braund (2004, p. 18) afirma que já as biografias antigas de Juvenal não são confiáveis por terem como fonte de informações apenas sua obra poética. William Anderson (1982, p. 3-4), ciente de que essa visão do texto como uma fonte biográfica advinha desde o tempo de escrita da obra juvenaliana, afirma que "a sátira romana é um dos sofredores mais pacientes da nossa ignorância". ${ }^{3}$ Essa crítica de Anderson parte da sua observação de que quando um estudioso toma como verdade empírica o que afirma um satirista em seu texto, o estudo perde em profundidade. $\mathrm{O}$ autor exemplifica essa opinião citando a atitude dos críticos da obra do primeiro satirista romano Lucílio: como a voz de seus poemas declara sua espontaneidade e confessa a própria falta de habilidade poética, o crítico, ao aceitar essas declarações como verdade sobre o poeta que as escreveu, deixa de trabalhar esse texto como um artefato poético e passa a analisálo enquanto fonte de informações biográficas e históricas - o que não aconteceria com um poema de Virgílio, por exemplo. Já Vasconcellos (2016, p. 19) aponta outro problema causado por essa abordagem: a tendência, por parte do pesquisador, a sujeitar o texto à visão de autor que sobre ela se projeta, ou seja, porque se tem uma imagem específica do autor daquela obra, há um esforço para que a obra corresponda a essa imagem, ainda que esta advenha de estereótipos. Em suma, o que aprendemos a partir dos estudos de Anderson e Vasconcellos é que ver o texto como mero pretexto para acessar seu autor empírico ou seu

\footnotetext{
${ }^{1}$ Demonstram esse entendimento da crítica de que a indignação é o que define a sátira juvenaliana os títulos de obras sobre o autor, como Vitorino (2003), que chama Juvenal de "satírico indignado", ou as observações de que ele mal pode conter a sua raiva, como em Freundeburg (2004, p. 209).

${ }^{2} \mathrm{O}$ primeiro texto em que William Anderson aborda o conceito de persona é Anger in Juvenal and Seneca, de 1964; no entanto encontra-se a apresentação desse conceito também no trabalho Essays on Roman Satire, de 1982, que é o texto a que temos acesso e ao qual nos referiremos.

3 "One of the most patient sufferers from our ignorance is Roman poetic satire" (Anderson, 1982, p. 3-4).
} 
contexto histórico de produção é empobrecer e esvaziar a análise textual, mas, sobretudo, desconsiderar ou desvalorizar qualquer trabalho intelectual e poético implicado na produção daquele texto. Perceber que Juvenal se apresenta em seus primeiros poemas com uma voz agressiva e supor que o poeta assim o faça pela necessidade de desabafar sobre aquilo que ele de fato sente é entender todo o texto como um rompante espontâneo e, como sugere a espontaneidade, desprovido de qualquer cuidado ou polimento naturalmente esperado de um texto que se proponha literário e pertencente a um gênero específico - no presente caso, a sátira romana.

Em um esforço por descaracterizar as sátiras como textos espontâneos e confessionais, e por perceber a carência de análises que façam jus aos poemas satíricos, William Anderson (1982, p. 3) propõe a aplicação do conceito de persona satírica, que estabelece a distinção entre o que afirma um poema escrito em primeira pessoa e o que realmente sente o poeta que o escreveu. Nesse sentido, se o crítico Gilbert Highet, em seu Juvenal the satirist: a study (1954), procura na obra de Juvenal a vida e as opiniões do poeta e as motivações para essas opiniões, Anderson parte da consciência de que aquele ego que já desponta no primeiro verso da primeira sátira ${ }^{4}$ não corresponde a Juvenal falando de si mesmo, mas à persona que o poeta conscientemente constrói para aquele texto. Dessa forma, se na visão de Highet a mudança de tom da obra juvenaliana ocorre por uma mudança pessoal de postura por parte de Juvenal, a justificativa de Anderson para esse fenômeno é que o poeta tenha adotado personae satíricas diferentes ao longo de sua obra.

Hodiernamente pode-se dizer que o conceito de persona proposto por Anderson obteve uma ampla aceitação, de tal forma que, para Susanna Braund (2004, p. 1), a leitura biografista, a que denomina "falácia biográfica", está superada pelo conceito de persona. Parece claro que o elemento gerador do equívoco inicial que ocasionou a leitura biografista de sátiras parece ser a escrita em primeira pessoa, combinada, porém, a um esquecimento de que todo texto da Antiguidade é escrito em função de um decoro genérico e de um esquema retórico, que preside a realização de todo o escrito. Como Cairns (2007, p. 31) já amplamente demonstrou, toda a poesia clássica se constitui a partir de preceitos vinculados aos vários gêneros, descritos em grande parte pela Retórica Antiga, ou acessados pelo próprio estudo de obras literárias sobreviventes. A teorização retórica antiga nos legou um conceito que, se próximo ao conceito de persona de Anderson, parece extrapolá-lo: o conceito de ethos.

Aristóteles é o primeiro teórico que chegou a nós em cuja obra o conceito de ethos se estabelece, ao afirmar que a persuasão pode ser atingida pelo caráter pessoal do que enuncia, ou antes, pela construção deste falante dentro do próprio discurso, tornando-o crível (Rhet. 1356 4 4-12). No entanto, outras obras da Antiguidade (como a Rhetorica Ad Herennium, de Cícero e a Institutio Oratoria, de Quintiliano), também passeiam em torno deste conceito, ainda que a cada momento ele pareça um pouco diverso: Quintiliano o aproxima do pathos, considerando-os intensidades diversas de efeito, por exemplo. Mais recentemente, a Análise

\footnotetext{
4 "Semper ego auditor tantum?" (1.1). "Sempre devo eu apenas ouvir?”. Esta tradução, como as outras do texto de Juvenal usadas neste artigo, pertencem a Francisco Antonio Martins Bastos.
} 
do Discurso de linha francesa tem desenvolvido o conceito de ethos, baseado no conceito da Antiguidade, mas para além dele. Por isso, aqui usamos o conceito conforme a AD, por entendermos que nos fornece uma definição completa, concisa e inambígua.

Um aspecto fundamental característico da sátira que aqui convém mencionarmos, porque em nossa análise ele ficará evidente, é o apreço pela hipérbole. Susanna Braund (2004, p. 4) já alertava ser problemática a interpretação das sátiras romanas como representação de costumes sociais, pois, por trás do aparente realismo, haveria ali uma distorção em alto grau com finalidade cômica. Similarmente, João Adolfo Hansen (2011, p. 167) afirma: "antes de ser psicológica ou expressiva, ou verista e realista, a sátira é um gênero retórico-poético de convenções para a caricatura". Portanto, é necessário ter em mente que o descomedimento de Juvenal é consciente e atende ao que se espera do gênero que ele escreve; em outras palavras, é preciso ter em mente que o satirista, como qualquer outro autor em qualquer outro gênero do discurso, procede a uma construção de ethos, que atende às necessidades do seu texto mais do que à veracidade com seu contexto. O ethos discursivo, segundo Maingueneau (2010, p. 79), está sempre presente na enunciação, pois a partir do momento em que o destinatário entra em contato com o discurso, ele necessariamente constrói uma imagem de quem seja aquele locutor, enquanto o locutor tenta controlar essa imagem de forma mais ou menos consciente e de uma maneira variável, a depender dos gêneros do discurso. Maingueneau segue uma linha teórica de descentralização do sujeito, pois o entende como reprodutor de um discurso comum a outros sujeitos que partilhem da mesma ideologia que ele; logo, a voz que emerge da enunciação se associa a um corpo enunciante que é situado sócio-historicamente. O destinatário, no processo de leitura, fará associações a certos estereótipos positivos ou negativos que se relacionam a esse locutor (Maingueneau, 2010, p. 80).

Como partimos do princípio de que a voz enunciadora na sátira não é necessariamente uma representação de quem a escreveu, mas uma construção textual consciente com uma determinada finalidade, entendemos que o ethos discursivo satírico é construído com vistas a um grupo social ao qual a persona satírica parece querer se vincular. Para que permaneça clara a nossa distinção entre autor empírico e persona, e para evitar a repetição, utilizaremos os termos "satirista" e "enunciador" como sinônimos, isto é, entendendo-o como uma instância discursiva. Assim, buscando compreender como se dá a construção da persona satírica de Juvenal no momento da transição das vozes, nos propusemos a analisar os primeiros duzentos e oitenta e cinco versos da Sátira 6 de Juvenal. Fizemos esse recorte pois, como observa Braund (2004, p. 230), esta sátira se destaca dentro do gênero por sua extensão: quase setecentos versos, uma escala épica, e não haveria espaço para tratar detalhadamente da sátira em sua totalidade.

\section{A SEXTA SÁtira}

A Sexta Sátira é um poema destinado a um interlocutor chamado Póstumo. Com vistas a tentar dissuadi-lo do casamento, o satirista se utiliza de diversas ofensas dirigidas ao gênero feminino. Timothy Haase (2013, p. 205) divide a sátira completa em três momentos principais: a cena da Idade de Ouro (6.1-20), o declínio de Roma (6.286-305) e, no último 
parágrafo, a justaposição de vilãs trágicas e mulheres romanas (6.634-660). Segundo Haase (2013, p. 203), no que diz respeito à indignatio juvenaliana, esta sátira pode ser considerada uma obra-prima. Para o autor, as ofensas direcionadas às mulheres na sátira em questão são desafios às noções de masculinidade e feminilidade em Roma. Haase, inclusive, sugere que um dos motivos pelos quais o satirista em Juvenal se opõe tão fortemente às mulheres seja porque as vê como uma ameaça não apenas para Roma, mas para sua empresa literária (Haase, 2013, p. 203).

Os dez versos que iniciam a sátira em questão retratam um casal em uma paisagem bucólica e simples. ${ }^{5}$ Como atenta Haase (2013, p. 208), comentadores da obra juvenaliana apresentam desconfiança diante do suposto tom elogioso com o qual o autor descreve a cena, pois, embora a imagem evocada pelo trecho seja saudosista, há, por exemplo, menção à quantidade de pelos da mulher e ao tamanho de seus seios. Esse contraste acarreta o que Haase chama de ambivalência referente à idealização do passado, a qual, segundo o autor, gera debate e divide os críticos em três escolas: a que acredita que o satirista de fato louva o passado; a que defende que o satirista retrate o passado sem amenizar seus detalhes mais impactantes; e por fim, a que imagina que o enunciador, ao utilizar tais termos, faça-o com o objetivo de zombar de quem louva o passado. Como em alguns versos adiante o enunciador afirma que os tempos eram diferentes na época que evoca, pois as pessoas então não tinham pais, mas nasciam de pedaços de carvalho ou moldes de lama, ${ }^{6}$ tendemos a preferir a hipótese da ironia travestida de saudosismo. Seguindo a formulação do ethos discursivo de Maingueneau segundo a qual inevitavelmente criamos uma imagem do nosso locutor a partir de sua enunciação, percebemos nessa comparação o despontar de um ethos que se manterá e se reforçará ao longo do texto: o nosso satirista é um insatisfeito em permanência, sem que exista uma solução que o contente. No trecho citado, percebemos de que forma essa insatisfação ocorre: se o tempo ideal era quando ainda não havia sociedade familiar, e não é possível nascer do carvalho ou da lama, então não existe solução para a contemporânea decadência moral subscrita nessa evocação, porque isso só seria possível se não existisse mais sociedade. Evidência dessa insinuação utópica do satirista é a comparação entre o

\footnotetext{
5 “Se houver pudor no Mundo, como eu creio,/ Foi reinando Saturno: largos dias/ Foi vista a pudicícia, quando os antros/Serviam às famílias de morada,/ De habitação aos Deuses, e de aprisco/ Aos gados. A mulher então robusta,/ De folhame, ou de colmo, ou de silvestres/ Brutos, com pele adornava o leito/ Nupcial, semelha a ti não sendo/ A Cíntia, nem a ti, Lésbia, que morto/ Pranteaste um Pardal! Mas presentava/ Aos vigorosos filhos fartos peitos./ Ela era muitas vezes, mais que o Esposo/ Que de robles vivia, dura, e forte." Original: Credo Pudicitiam Saturno rege moratam/ in terris visamque diu, cum frigida parvas/ praeberet spelunca domos ignemque laremque/ et pecus et dominos communi clauderet umbra, / silvestrem montana torum cum sterneret uxor/ frondibus et culmo vicinarumque ferrarum/ pellibus, haut similis tibi, Cynthia, nec tibi, cuius turbavit nitidos extinctur passer ocellos, / sed potanda ferens infantibus ubera magnis/ et saepe borridior glandem ructante marito.

6 "Era então novo o Mundo, e um Céu recente/ Cobria os homens, que sem Pais nascidos,/ Mas do limo tirados, ou de um tronco/ Por diversos costumes conviviam.” Original: Quippe aliter tunc orbe novo caeloque recenti/ vivebant homines, qui rupto robore natil compositive luto nullos habuere parentes (6.11-14).
} 
extinto - ou, a nosso ver, inexistente - modelo ideal de mulher e as musas de Propércio e Catulo, ambos poetas do século I a.C, que, para o satirista, seriam representativas, de forma ruim, das mulheres romanas.

Nos versos seguintes, o satirista então questiona a sanidade de Póstumo, porque este deseja se casar, e sugere que é preferível o suicídio ao casamento - e o fato de fazer isso por meio da listagem de formas de se matar sem dizer explicitamente que o está fazendo traz um tom humorístico ao trecho. ${ }^{7}$ A seguir, acrescenta que seria melhor até se relacionar com um jovem (pusio) a relacionar-se com uma mulher, pois estas fazem muitas reclamações. Percebe-se aí um topos que permanece contemporaneamente e que será reforçado em outros momentos na mesma sátira: o estereótipo da mulher como um gênero difícil de agradar, jamais satisfeito mesmo diante dos esforços masculinos.

Ao comentar, com tom surpreso, que o então galanteador Ursídio, um "moechorum notissimus" (6.42), ${ }^{8}$ pretende casar-se, o enunciador demonstra descrença quanto à probabilidade de ele encontrar uma noiva, já que procura uma moça "antiquis moribus" (6.45). ${ }^{9}$ Aqui temos nova evocação saudosa a um passado em que a moral era diferente e, portanto, as moças comportavam-se de forma mais adequada; mas que, como vimos, é um passado apenas ideal, por não ser passível de ter existido. O satirista dedica os versos de 114 a 135 para falar de Messalina, terceira esposa de Cláudio, morta a mando do imperador por, em meio a outras traições, ter se casado com Caio Sílio (Suetônio, De Vita Caesarum, V.26). Messalina aqui é descrita como a "meretrix Augusta" (6.117) ${ }^{10}$ que, com frequência, ao adormecer do marido, ia para um bordel, de onde saía apenas relutantemente. O satirista praticamente não menciona Cláudio, e esse aspecto - em conjunto com a ausência de qualquer insinuação de que o imperador tivesse algum nível de culpa por viver naquela situação, já que, se era fato tão conhecido de todos, não deveria ser de seu completo desconhecimento -, coloca-o em posição de vítima e, por conseguinte, enfatiza a vilania do comportamento de Messalina. A escolha pelo posicionamento de expor os atos vis da imperatriz sem envolver o imperador sugere uma aprovação, por parte do satirista, de Cláudio e seu governo, pois se houvesse qualquer ímpeto de atribuir os problemas de Roma à má gestão de seus governantes, esse seria o contexto mais propício - afinal, seria fácil dizer que um imperador que não conseguia ter controle sobre a própria esposa jamais conseguiria fazê-lo com o resto do império.

Percebe-se, pela forma como o enunciador menciona a questão conjugal de Cláudio, uma certa justificativa para o ethos de incurável insatisfação que tem sido demonstrado com tanta clareza até então: a indignação tem raiz na discrepância da qualidade de caráter dos homens em relação ao das mulheres. Messalina aparece aqui como uma figura representativa de todas as mulheres, ao passo que o comportamento ingênuo do imperador é considerado

\footnotetext{
7 “(...) Sofrer mulheres/ Com tantas cordas, com janelas tantas/ Com que te enforques, donde te despedaces, / E a ponte Emiliana onde te afogues". Original: Ferre potes dominam salvis tot restibus ullam,/ cum pateant altae caligantesque fenestrae, cum tibi vicinum se praebeat Aemilius pons? (6.30-32)

8 "O maior dos adúlteros".

9 "Que as antigas imita em bons costumes"

10 "A real meretriz".
} 
um padrão, tendo em vista a ausência de críticas por parte do satirista, como há pouco observamos. Como prevê Maingueneau, o locutor pode tentar controlar em certa medida o próprio ethos, e este é o momento em que podemos perceber essa tentativa de controle de forma mais evidente, pois a partir do momento em que a persona satírica traz uma situação ilustrativa entre um homem e uma mulher e só tece críticas ao comportamento feminino, fica subentendido que sua postura é de concordância com a conduta do homem mencionado - o imperador -, já que esta corresponde ao que se espera. Aqui, a imagem que se constrói dos homens é de transparência: o imperador dorme tranquilamente durante a noite, pois não precisa fazer nada que não faria à luz do dia, e enquanto descansa na própria retidão de caráter é que recebe a traição de sua esposa.

O satirista critica também a união com uma mulher mais rica que o marido, pois o dinheiro compraria sua própria liberdade para ser adúltera. Assim, podia considerar-se solteira a mulher que se casasse com um homem ganancioso (6.141), ${ }^{11}$ já que o dinheiro seria de maior importância para esse marido do que a fidelidade. Um pouco adiante, no entanto, acusa esposas de serem consumistas e exigirem que seus maridos comprem tudo o que elas veem (6.152). ${ }^{12}$ Percebe-se, portanto, que, para o satirista, a relação da mulher com o dinheiro é sempre problemática: se é rica, será infiel ao marido; se dele depende, será exploradora.

Curioso, no entanto, é quando, nos versos 161-166, o satirista admite que uma mulher que fosse perfeita e atingisse a todas as suas exigências também seria insuportável. ${ }^{13}$ Para o enunciador, alguém com muita dignidade - e usa como exemplo Cornélia, mãe de Tibério e Caio Graco - veria seus triunfos como parte de seu dote e seria tão orgulhosa de si que inferiorizaria o marido. A explícita admissão do enunciador de que mesmo a mulher perfeita, no sentido de não ser culpada em nenhuma de suas críticas, não seria realmente perfeita e, portanto, não se eximiria de receber novas críticas, é um reforço de que a persona, nesta sátira, parte de um modelo inexistente de mulher para criticar a conduta das mulheres reais. Aqui existe mais um reforço ao ethos de incurável insatisfeito que o satirista tem constantemente demonstrado. Não apenas a valoração do real a partir de uma comparação ilógica demonstra, a nosso ver, que o satirista é explícito em sua ausência de motivações consistentes para suas críticas, como o reconhecimento da impossibilidade de perfeição é uma prova da gratuidade de sua aversão às mulheres e, em específico, a casar-se com elas.

\footnotetext{
11 "Rica, ao avaro unida, é qual solteira". Original: (...) vidua est, locuples quae nupsit avaro.

12 "[Pede lhes compre] Quanto em casa não tem, e vê na alheia". Original: quodque domi non est, sed habet vicinus, ematur.

13 “Então; mulher de nós nenhuma é digna?/ Há formosas, discretas; ricas, sábias,/ Que de ilustres Avós os átrios ornam,/ Mais puras que as Sabinas, que impediram/ Com preces suas, desgrenhada coma,/ A dura guerra, cujo objeto foram! Com estas condiçoes; mulher no mundo, / Mais custa achar-se do que Cisne preto!/ Quem tal menina suportar se atreve?" [grifos do tradutor]. Original: Nullane de tantis gregibus tibi digna videtur?"/ sit formonsa, decens, dives, fecunda, vetustos/ porticibus disponat avos, intactior omni/ crinibus effusis bellum dirimente Sabina, / rara avis in terris nigroque simílima cycno, / quis feret uxorem cui constant omnia?
} 
Dando continuidade à ideia de que nenhuma mulher é perfeita, questiona quem já foi tão devoto à própria esposa que não a odiasse pela maior parte do tempo (6.181-183). ${ }^{14}$ Mais adiante, declara que quem gosta da esposa deve estar preparado para ficar sob jugo da mesma, pois não há mulher que poupe a quem a ama (6.208). ${ }^{15}$ A mulher, então, é construída como um ser difícil de ser amado e desprovido da capacidade de amar verdadeiramente. Não apenas será infiel na primeira oportunidade, como será insensível ao amor do marido, utilizando-se desse afeto para conseguir dominá-lo.

O satirista, nos versos $231-241,{ }^{16}$ acusa a sogra de transmitir para a filha todos os comportamentos viciosos dos quais se queixa nos versos anteriores. Essa atitude adiciona ao ethos de insatisfação a descrença diante de qualquer possibilidade de mudança ou diminuição da criticada degeneração: se o problema são hábitos viciosos por parte das mulheres, e se esses hábitos se tornaram culturais no sentido de serem ensinados ao longo das gerações, não é possível prever um fim dessa reprodução de costumes reprováveis. A maternidade aqui é representada como danosa por favorecer a perpetuação de uma espécie de "tradição" feminina que deveria acabar, pois é dessa tradição que se originam todos os problemas de que padecem os homens que se casam com mulheres.

Nos versos $268-285,{ }^{17}$ os últimos de nossa análise, o satirista afirma que dividir a cama com a esposa não permite ao marido muito sono, pois a culpa que a mulher sente

14 “Quem tanto a mulher preza, que no dia/ Vezes não maldiçoe sete a mesma/ Que exalta com encômios outras vezes?”. Original: (...) quis deditus autem/ usque adeo est, ut non illam quam laudibus effert/ horreat inque diem septenis oderit horis?.

${ }^{15}$ [A esposa nenhuma] Mágoa poupa ao marido mais amável”. Original: (...) nullam invenies quae parcat amanti.

16 “Descanso não esperes, viva a Sogra,/ Que roubar seu Marido à filha ensina,/ Ela dita cartinhas, de alto estilo,/ Que aos amantes envia a filha; engana,/ Ou com dádivas compra os mesmos guardas;/ Tendo saúde, Arquígenes consulta;/ De si lança os vestidos mais pesados,/ O adúltero entretanto exasperado,/ Impaciente espera em feios atos./ Cuidas que há-de ensinar-lhe os bons costumes,/ Que não professa? A desonesta velha/ Desonesta educar convém-lhe a filha!’. Original: Desperanda tibi salva concordia socru. / illa docet spoliis nudi gaudere mariti, / illa docet missis a corruptore tabellis/ nil rude nec simplex rescribere, decipit illal custode aut aere domat. Tum corpore sano/ adovcat Archigenen onerosaque pallia iactat. / aditus interea latet et secretus adulter, / impatiensque morae silet et praeputia ducit./ scilicet expectas ut tradat mater honestos/ atque alios mores quam quos habet? Utile porro/ filiolam turpi vetulae producere turpem.

17 "No leito conjugal questões renhidas/ Sempre se excitam, sempre o sono afastam./ A que o Esposo ofendeu é mais sanhuda,/ Que a Tigre, a quem roubaram os filhinhos,/ Finge ocultos gemidos, largo pranto,/ Que está pronto nos olhos refasados/ Para o momento, em que lhe apraz soltá-lo./ Odeia os filhos; ter rivais simula/ Tu julgas isto amor, ah! Cucozinho?/ Suas lágrimas limpas! Que disseras / Se as cartas amatórias, se escritinhos/ Da adúltera ciosa ler pudesses!/ Que nos braços do servo, ou Nobre existe./ Quintiliano amigo, nas figuras / Que desculpa Retóricas deparas/? Eu? Com isso Retóricas não valem!/ Dize pois tu, Mulher! Entra em contato/ Fazer o esposo meu quanto quisesse,/ Eu a contento meu, dar-me aos prazeres:/ Posto clames, e o Mar c’o Céu confundas,/ Sou Mulher; dito está... Ao desaforo/ Da achada em adultério, nada chega!/ O crime a faz irosa, e vã soberba". Original: Semper habet lites alternaque iurgia lectus/ in quo nupta iacet; minimum dormitur in 
pelos próprios pequenos delitos faz com que ela desconte no marido, fingindo chateações; diz também que as mulheres sempre têm várias lágrimas guardadas à espera pelo momento exato em que decidem derramá-las; e, além disso, sugere um momento de flagrante em que, quando o marido encontrasse as cartas trocadas com amantes, as esposas diriam apenas que eram humanas - e, portanto, teriam direito de errar. Percebe-se aqui um suposto mapeamento do padrão comportamental feminino: a mulher que se queixa para manipular o marido, desconta nele uma raiva gerada pela própria culpa por saber que age mal e, por fim, ao ser descoberta em práticas indignas, apela para a diminuição da própria responsabilidade sobre o que fez, pois isso se deveria a qualquer impulso incontrolável inerente à espécie humana.

\section{ConClusão}

À guisa de conclusão, percebe-se, em nosso exame do recorte selecionado, que o enunciador desta sátira apresenta um ethos conservador e extremamente avesso a mulheres, retratadas como manipuladoras, exploradoras, adúlteras e, ainda, conscientes desse comportamento, já que haveria uma atitude consciente de ensinamento dessas condutas por parte das mães para as filhas e uma defesa pronta e irrebatível - uma tendência natural da espécie humana. A personalidade feminina de modo geral é retratada como tão desgastante que o único motivo para um homem conseguir passar por todas as desvantagens de estar com uma mulher seria a satisfação visual, pois ama-se o rosto, não a esposa $(6.143-144)^{18}$ - mas, tal como a beleza, essa disposição teria prazo de validade. O ethos predominante é de um saudosista utópico, que lamenta a degradação moral contemporânea, mas que também é descrente de qualquer possibilidade de melhora, e utiliza como parâmetro de comparação um tempo em que não viveu e que, portanto, não existe. $O$ supracitado exagero típico do gênero pode ser observado sobretudo na própria confissão do satirista de que nem a mulher perfeita seria perfeita. Esta declaração praticamente neutraliza todas as suas críticas e opiniões, já que ele se torna um admitido insatisfeito impossível de ser agradado. Concordamos com Haase (2013, p. 203) quando afirma que a indignatio juvenaliana, portanto, de fato se cumpre como uma obra-prima na Sátira 6, e a nosso ver isso se dá porque o satirista deixa transparecer a gratuidade de sua agressão. Se, por um lado, ocorre-nos o pensamento de que, já que não é possível agradar a esse enunciador e ele mesmo sabe disso, então por que reclamar? -, por outro, chegamos ao que acreditamos ser o raciocínio que ele prefere seguir: por que não?

illo. / tum gravis illa viro, tunc orba tigride peior, / cum simulat gemitus occulti conscia facti, / aut odit pueros aut ficta paelice plorat/ uberibus semper lacrimis semperque paratis/ in statione sua atque expectantibus illam, / quo iubeat manare modo. tu credis amorem, / tu tibi tunc, uruca, places fletumque labellis/ exorbes, quae scripta et quot lecture tabellas/ si tibi zelotypae retegantur scrinia moechae!/ sed iacet in servi complexibus aut equitis. 'dic,/ dic aliquem sodes bic, Quintiliane, colorem.'/ 'baeremus. Dic ipsa.' 'olim convenerat' inquit/ 'ut faceres tu quod velles, nec non ego possem/ indulgere mihi. clames licet et mare caelo/ confundas, homo sum.' nibil est audacius illis/ deprensis: iram atque animos a crimine sumunt.

18 "Por que razão de Bíbula Sertório/ Arde em amor? Se inquires a verdade,/ Nela a beleza, e não virtude indaga”. Original: 'Cur Desiderio Bibulae Sertorius ardet?'/ si verum excutias, facies non uxor amatur. 


\section{REFERÊNCIAS}

ANDERSON, William. Anger in Juvenal and Seneca. University of California Publications In Classical Philology, Berkeley, v. 19, n. 3, p. 127-96, 1964.

ANDERSON, William. Essays on Roman satire. Princeton: Princeton University Press, 1982.

ARISTOTLE. Rhetoric. Ed. William David Ross and Transl. W. Rhys Roberts. New York: Cosimo Classics, 2010.

BRAUND, Susanna. Introduction. In: JUVENAL; PERSIUS. Juvenal and Persius. Edited and translated by Susanna Morton Braund. Loeb Classical Library. Cambridge: Harvard University Press, 2004. p. 1-39.

CAIRNS, Francis. Generic composition in Greek and Roman poetry. Ann Arbor: Michigan Classical Press, 2007.

CARMO, Rafael Cavalcanti do. As manifestações do cômico nas "saturae" de Jwvenal. 2014. $142 \mathrm{f}$. Dissertação (Mestrado em Letras) - Programa de Pós-Graduação em Letras, Universidade Federal do Espírito Santo, Vitória, 2014.

CÍCERO. Retórica a Herênio. Tradução de Ana Paula Celestino Faria e Adriana Seabra. São Paulo: Hedra, 2005.

FREUDENBURG, Kirk. Satires of Rome. Threatening poses from Lucilius to Juvenal. Cambridge: Cambridge University Press, 2004.

HAASE, Timothy Michael. Watching the world unravel. Juvenal's satirical mechanics. 2005. $283 \mathrm{f}$. Tese (Doutorado em Filosofia) - Departamento de Clássicas, Brown University, Providence, 2013.

HANSEN, João Adolfo. Anatomia da sátira. In: VIEIRA, Brunno V. G.; THAMOS, Márcio. Permanência Clássica. Visões contemporâneas da Antiguidade greco-romana. São Paulo: Escrituras, 2011.

HIGHET, Gilbert. Jwenal the satirist. A study. New York: Oxford University Press, 1954.

HOOLEY, Daniel. Roman satire. Oxford: Blackwell, 2007.

JUVENAL. Sátiras. Trad. Francisco Antônio Martins Bastos. Rio de Janeiro: Ediouro, [s/d.].

JUVENAL \& PERSIUS, Jwenal and Persius. Edited and translated by Susanna Morton Braund. Cambridge: Harvard University Press, 2004.

KIGHT, Charles. The Literature of Satire. Cambridge: Cambridge University Press, 2004.

LEITE, Leni Ribeiro; CORDEIRO, Iana Lima. A construção satírica no Livro I de Juvenal. Caliope: Presenşa Clássica, Rio de Janeiro, v. 1, n. 33, p. 5-20, dez. 2017. Disponível em: <https:/ / revistas.ufrj.br/index.php/caliope/article/view/12798>. Acesso em: 01 jun. 2018.

MAINGUENEAU, Dominique. Doze conceitos em Análise do Discurso. São Paulo: Parábola, 2010. 
MARTIAL. Epigrams. Edited and translated by D. R. Shackleton Bailey. Cambridge, Mass.: Harvard University Press, 1993. 3 v.

QUINTILIAN. Institutio Oratoria. Ed. Harold Edgeworth Butler. Loeb Classical Library. Cambridge: Harvard University Press, 1920.

SUETÔNIO. A vida dos doze Césares. Apresentação de Carlos Heitor Cony. Tradução de SadyGaribaldi. Rio de Janeiro: Tecnoprint, 1985.

VASCONCELLOS, Paulo Sérgio de. Persona poética e autor empirico na poesia amorosa romana. São Paulo: Editora Unifesp, 2016. 